\title{
Inhibiting Effect of Dioctyl Phthalate on the Corrosion of Mild Steel in 1.0 M Hydrochloric Acid Solution
}

\author{
Michael Emmanuel'1, Bethrand T. Nwufo'², Mbanefo M. Ekwenchi ${ }^{2}$ \\ ${ }^{1}$ Department of Chemistry, Gombe State University, Gombe, Nigeria \\ ${ }^{2}$ Department of Pure and Industrial Chemistry, University of Jos, Jos, Nigeria \\ Email: e.michael86@outlook.com
}

How to cite this paper: Emmanuel, M., Nwufo, B.T. and Ekwenchi, M.M. (2018) Inhibiting Effect of Dioctyl Phthalate on the Corrosion of Mild Steel in 1.0 M Hydrochloric Acid Solution. Open Access Library Journal, 5: e4927.

https://doi.org/10.4236/oalib.1104927

Received: September 18, 2018

Accepted: October 28, 2018

Published: October 31, 2018

Copyright $\odot 2018$ by authors and Open Access Library Inc.

This work is licensed under the Creative Commons Attribution International License (CC BY 4.0).

http://creativecommons.org/licenses/by/4.0/

(c) (i) Open Access

\begin{abstract}
Steel corrosion is a major and costly problem to industrialists and construction workers. The inhibiting effect of dioctyl phthalate on the corrosion of mild steel was carried out in $1.0 \mathrm{M}$ solution of $\mathrm{HCl}$ as the corrosion medium using the weight loss method. The adsorption of the dioctyl phthalate on the surface of the mild steel in $1.0 \mathrm{M} \mathrm{HCl}$ was found to follow the physisorption mechanism and also follow the first order rate law. The corrosion rate was found to be directly proportional to the temperature of the medium, and inversely proportional to the concentration of the inhibitor in solution. The activation energy increases with increase in the concentration of the inhibitor. Values of standard free energy change, $\Delta \mathrm{G}_{\text {ads }}^{\mathrm{o}}$ are consistently below -20 $\mathrm{kJmol}^{-1}$. This solidly established that the adsorption mechanism of the dioctyl phthalate on mild steel surface is physisorption. Langmuir and Freundlich adsorption isotherms were used, with Freundlich isotherm as best fit for the modelling of the adsorption process. The value $n_{F}$ in Freundlich isotherm which, indicates the intensity of adsorption, was found to be in the average of 0.717 not far from the typical value of $0.6 \mathrm{n}_{\mathrm{F}}$.
\end{abstract}

\section{Subject Areas}

Electrochemistry

\section{Keywords}

Mild Steel, Dioctyl Phthalate, Weight Loss, Corrosion Inhibition

\section{Introduction}

Corrosion is degradation of materials 'properties due to interactions with their 
environments, and corrosion of most metals (and many materials for that matter) is inevitable. While primarily associated with metallic materials, all material types are susceptible to degradation [1]. Degradation of polymeric insulating coatings on wiring has been a concern in aging aircraft. Even ceramics can undergo degradation by selective dissolution. Like death and taxes, corrosion is something we hope to avoid; but ultimately it is something we must learn to deal with [2]. The fundamental cause or driving force for all corrosion is the lowering of a system's Gibbs energy [3].

There are basically five methods of corrosion control, these are: material selection, coating, inhibitors, design and cathodic protection. For the sake of this research, the method of corrosion control employed is the use of inhibitors. Corrosion inhibitors are substances, which when added to a solution, reduces the rate at which a material mostly metals deteriorate [4]. Corrosion inhibition is often attained by the formation of a coating of the inhibiting material on the surface of the metal. For example, Benzotriazole inhibits corrosion of copper by forming an inert layer of this polymer on the metal's surface [5].

The study of the mechanism of corrosion and corrosion inhibition of Tin in aqueous solutions containing tartaric acid was conducted by Rabab and Waheed [6]. They discovered that with only the solution of tartaric acid, the dissolution of the tin was enhanced, but an introduction of about $0.02 \mathrm{~mol} \cdot \mathrm{dm}^{-3}$ of a naturally occurring glycine inhibits the rate of corrosion by $30 \%$.

Onen, et al. [7] studied the inhibition properties of titanium oxide for aluminium and mild steel using the method of absorbance difference. They found that there is an increase in percentage inhibition as the concentration of the titanium (IV) oxide also increases. They attributed the inhibition efficiency of the titanium (IV) oxide to the presence of lone pair of electrons on the oxygen which is delocalized and provides resonance stability to the compound [7].

Organic inhibitors are the most widely used nowadays, owing to the fact that they are environmentally friendly. The organic type inhibitors studied are the azoles and their derivatives, imidazoles, amines and their derivatives, amino acids-which, are considered the most non toxic organic compounds, highly soluble in aqueous media and produced with high purity and at low cost; triphenylmethane derivatives, thiol group compounds, organic derivatives of phosphates such as inositol hexaphosphates, potassium ethyl xanthate, etc. [8].

Dioctyl phthalate (DOP) with IUPAC nomenclature dioctyl benzene-1,2-dicarboxylate, is a clear, colourless, and viscous liquid with a slight, characteristic odor, soluble in ethanol, ether, mineral oil, and the majority of organic solvents, immiscible with water, resistant to hydrolysis and air oxygen activity. The major applications of DOP are found in plastic industry for plasticizing plastic, wood coatings, manufacture of medical and sanitary equipments such as blood bags and dialysis equipments and it is also applicable in the manufacture of capacitors as dielectric fluid, hydraulic liquid and solvent in light stick. It has a molecular weight of $390.6 \mathrm{gmol}^{-1}$, with a specific gravity of 0.98 at $25^{\circ} \mathrm{C}[9]$. 
This particular compound was selected for this research because, since most of the experiments involving corrosion studies was done using plant extracts. Attributing the inhibiting effect to one compound in the extract is difficult, hence posing difficulty in studying the mechanism of the adsorption. With a pure compound, which is readily available, studying the inhibiting properties will open doors for its application in industries.

\section{Method}

The method employed for the study of the inhibiting properties of Dioctyl phthalate in $\mathrm{HCl}$ is the weight loss method [10]. Coupons of mild steel of size 5 $\mathrm{cm}$ by $4 \mathrm{~cm}$ were used, and concentration of the inhibitor ranges from 0.01 $\mathrm{mol} \cdot \mathrm{dm}^{-3}$ to $0.07 \mathrm{~mol} \cdot \mathrm{dm}^{-3}$, in $1.0 \mathrm{M} \mathrm{HCl} \mathrm{[10].} \mathrm{The} \mathrm{immersion} \mathrm{time} \mathrm{was} 1-3 \mathrm{hrs}$ and temperature ranges of $303 \mathrm{~K}$ to $313 \mathrm{~K}$.

\section{Determination of Parameters}

The percentage inhibition efficiency $\% \mathrm{IE}$, the surface coverage $\theta$, and the corrosion rate $C_{r}$ were determined from Equations (1)-(3) respectively.

$$
\begin{gathered}
\% \mathrm{IE}=\left[1-\left(\frac{W_{0}-W_{t}}{W}\right)\right] \times 100 \\
\theta=1-\left(\frac{W_{0}-W_{t}}{W}\right)
\end{gathered}
$$

where $W_{0}=$ initial weight of the mild steel before suspending in the solutions, $W$ = weight of the mild steel without the inhibitor, that is, weight in blank solution, and; $W_{t}=$ weight of the mild steel after inhibition the inhibitor

$$
C_{r}\left(\mathrm{mg} \cdot \mathrm{cm}^{-2} \cdot \mathrm{hr}^{-1}\right)=\frac{W_{0}-W_{t}}{A T}
$$

where $A=$ surface area of the coupon $\left(\mathrm{cm}^{2}\right), T=$ time of exposure in hrs, $W_{0}-$ $W_{t}=$ weight loss.

The inhibitor efficiency gives important information about the performance of the inhibitor in various medium [11].

The activation energy of adsorption $\mathrm{E}_{\mathrm{ads}}$, Enthalpy and entropy of adsorption $\mathrm{H}_{\mathrm{ads}}$ and $\mathrm{S}_{\mathrm{ads}}$, and free energy change of adsorption $\Delta \mathrm{G}_{\mathrm{ads}}$ were determined from the following Equations (4)-(6) respectively.

$$
\ln C_{r}=\ln A-\left(\mathrm{E}_{\text {ads }} / R T\right)
$$

where $C_{r}=$ rate of corrosion, $A=$ a frequency factor, $R=$ Gas constant (Atm. L. $\left.\mathrm{mol}^{-1} \cdot \mathrm{K}^{-1}\right), T=$ temperature $(\mathrm{K})$.

A plot of $\ln C_{r}$ against $1 / T$, gives a straight line, with slope equals to $\mathrm{E}_{\text {ads }} / R$ and an intercept of $\ln A$. [12]. The values of $\mathrm{E}_{\mathrm{a}}$ greater than $20 \mathrm{~kJ}$ indicate that the adsorption process is controlled by the surface reactions [13]

$$
\ln \frac{C r}{T}=\ln \frac{R}{N h}+\left(\frac{\Delta \mathrm{S}_{\mathrm{ads}}}{R}\right)-\left(\frac{\Delta \mathrm{H}_{\mathrm{ads}}}{R T}\right)
$$

where $R$ = gas constant, $N=$ Avogadro's number $6.03 \times 10^{23} \mathrm{~mol}^{-1}, h=$ the 
Planck's constant $6.62 \times 10^{-34} \mathrm{Js}$

A plot of $\ln C_{r} / T$ against $1 / T$ is a straight line with a slope equal to $\frac{\Delta \mathrm{H}_{\text {ads }}}{R T}$ and the intercept of the graph is equal to $\ln \frac{R}{N h}+\left(\frac{\Delta \mathrm{S}_{\mathrm{ads}}}{R}\right)$. The values of $\Delta \mathrm{H}_{\text {ads }}$ indicates whether the adsorption process absorbed heat $(+\Delta \mathrm{H})$ or releases heat $(-\Delta \mathrm{H})[14]$

$$
\Delta \mathrm{G}_{\mathrm{ads}}=-R T\left(\ln 55.5 \mathrm{~K}_{\mathrm{ads}}\right)
$$

where $\mathrm{K}_{\mathrm{ads}}$ is the equilibrium constant for the adsorption of the inhibitor on mild steel surface [15]

Other parameters determined are the rate constant for the adsorption process $\mathrm{k}$, and the half life of the metal in the presence of the inhibitor according to Equation (7) and Equation (8).

$$
\ln w_{f}=\ln w_{i}-k t
$$

where $w_{i}$ and $w_{f}$ are respectively the weights of the mild steel in blank acid solution and after immersion in the inhibitor solution. This value tells how fast the adsorption process is taking place. A plot of $\ln \left(w_{i} / w_{f}\right)$ against $t$, gives a straight line with a slope which is equal to $k$.

$$
t_{1 / 2}=\frac{\ln 2}{k}
$$

where $t_{1 / 2}=$ half-life of the mild steel.

Freundlich and Langmuir adsorption isotherms (Equation (9), and Equation (10)) were used to model thee adsorption process.

$$
\begin{gathered}
\text { Freundlich } \log \theta=\log k+n \log C \\
\text { Langmuir }\left(\frac{C}{\theta}\right)=\frac{1}{k}+C
\end{gathered}
$$

where $k$ is the equilibrium constant, $C$ is the concentration of the inhibitor, $\mathrm{n}$ is a constant which tells the intensity of the adsorption process, and have a typical value of $0.6[16]$.

\section{Results and Discussion}

The variation of the rate of corrosion of mild steel at different concentration of inhibitor solution in $1.0 \mathrm{M} \mathrm{HCl}$ solution as the corrodant and at different temperatures is shown in Figures 1-3. The Figures show the effect of exposure time, and the concentration of the inhibitor on the corrosion rate of the mild steel. From the Figures, it is clear that corrosion rate decreases with increase in concentration of the inhibitor and decrease with time of exposure to the inhibitor solution [17].

The effect of temperature is shown in Figure 4. Corrosion rate increases with increasing temperature from $303 \mathrm{~K}$ to $313 \mathrm{~K}$, and the corrosion rate decreases with increase in the concentration of the inhibitor. This is because as the concentration is increasing, more molecules of the inhibitor become available to 


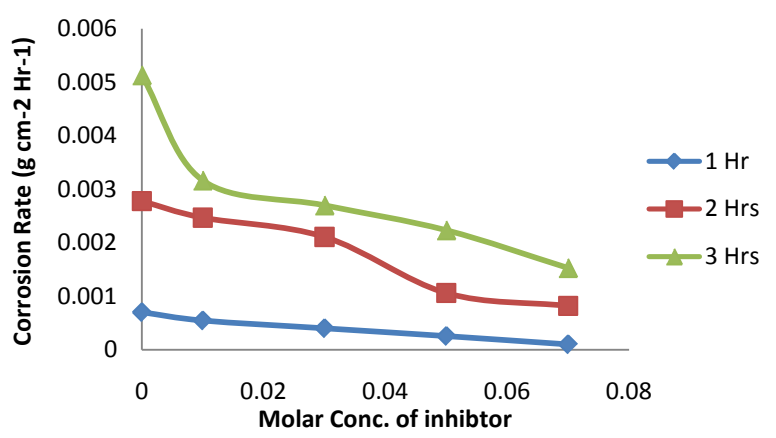

Figure 1. Variation of Corrosion rate with conc. of inhibitor in $1.0 \mathrm{M} \mathrm{HCl}$ solution at $303 \mathrm{~K}$.

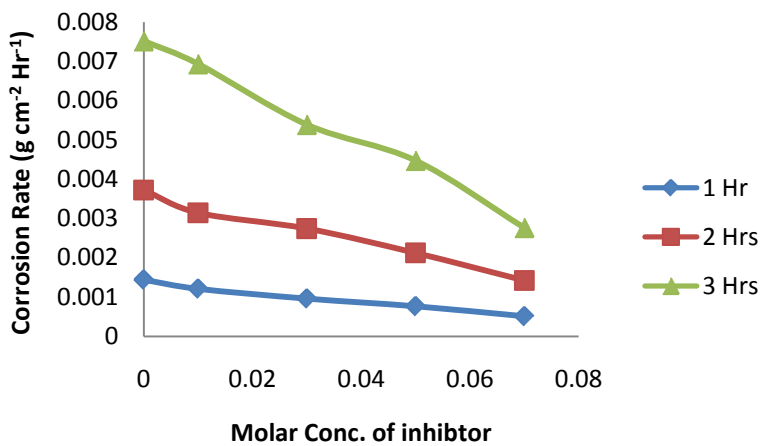

Figure 2. Variation of Corrosion rate with conc. of inhibitor in $1.0 \mathrm{M} \mathrm{HCl}$ solution at $308 \mathrm{~K}$.

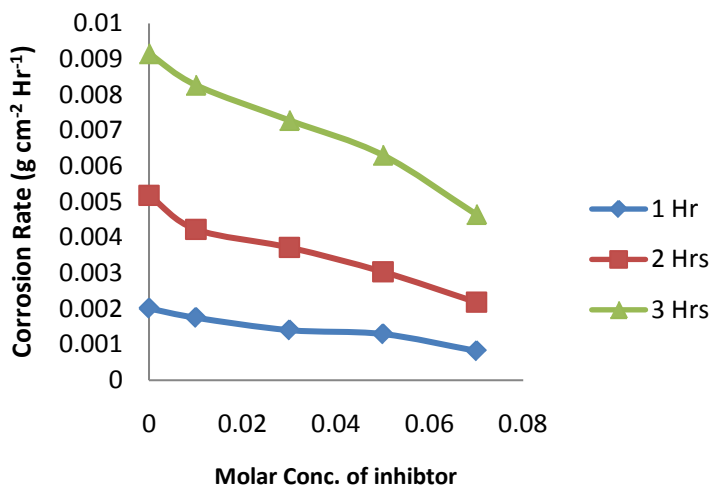

Figure 3. Variation of Corrosion rate with conc. of inhibitor in $1.0 \mathrm{M} \mathrm{HCl}$ solution at $313 \mathrm{~K}$.

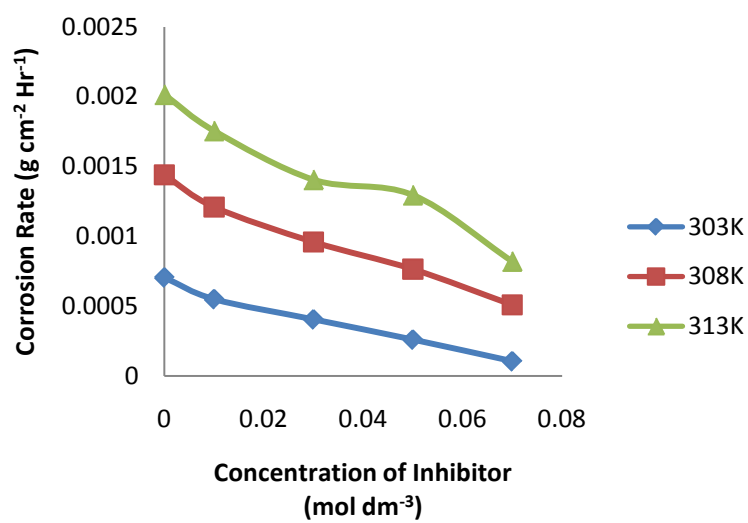

Figure 4. Effect of temperature on corrosion rate in $1.0 \mathrm{M} \mathrm{HCl}$ solution after $1 \mathrm{Hr}$. 
cover the surface of the mild steel, preventing it from coming in contact with the corrodant.

\section{1) Thermodynamic Considerations}

The activation energy $E_{\text {ads }}$ of the adsorption process is represented in Table 1. Generally, higher values of $\mathrm{E}_{\mathrm{ads}}$, in presence of additives support physical adsorption mechanism whereas an unchanged or lower value of $E_{\text {ads }}$ for inhibited systems compared to the blank is indicative of chemisorption mechanism. From Table 1, it can be seen that the values of the activation energies for the inhibited systems increases from $82.96 \mathrm{~kJ}$ for the uninhibited system to a maximum of $162.54 \mathrm{~kJ}$ for the inhibited system. This is an indication of a physisorption (a process in which the electronic structure of the adsorbed molecule is barely disturbed on adsorption) mechanism of adsorption [18].

The dissolution process of the mild steel is considered difficult if the values of the enthalpy of adsorption $\Delta \mathrm{H}_{\text {ads }}$ for the corrosion process in the blank and inhibited solution is found to be positive, indicating an endothermic process [19]. From Table 1, it can be seen that all the values of the $\Delta \mathrm{H}_{\text {ads }}$ are positive, hence the dissolution of mild steel in the solution of the inhibitor is difficult. The entropy of the inhibition process $\Delta \mathrm{S}_{\mathrm{ads}}$, as shown in Table 1 , a higher value of the entropy obtained in the presence of the inhibitor, showed that the recombination step is a more orderly arrangement compared to the initial state without the inhibitor [14]. It can be seen from Table 1 that the values of $Q_{a d s}$ are negative throughout and decreases as the concentration of the inhibitor decreases. This indicates that the adsorption of the inhibitor to the surface of the mild steel is spontaneous, and this is indicative of a strong interaction between the inhibitor and the mild steel [20].

It was also discovered that the values of $E_{\text {ads }}$ increases with increase in the concentration of the inhibitor. The values of $\mathrm{E}_{\mathrm{ads}}$ and those of $\Delta \mathrm{H}_{\mathrm{ads}}$ varies in a similar manner, and the average values of $\mathrm{E}_{\mathrm{ads}}-\Delta \mathrm{H}_{\mathrm{ads}}$ equal to $2.41 \mathrm{kJmol}^{-1}$, which is very close to the value of RT $\left(2.51 \mathrm{kJmol}^{-1}\right)$ indicating that the adsorption process is unimolecular in nature [21].

\section{2) Adsorption Studies}

The isotherms selected for the adsorption study are Langmuir and Freundlich. The isotherm parameters were calculated from Equation (9) and Equation (10) for Freundlich and Langmuir isotherm respectively. The values obtained are represented in Table 2.

The adsorption equilibrium constant $\mathrm{K}_{\mathrm{ads}}$ decreases with increase in experimental temperature in the corrosion media (Table 2), indicating that the interactions between the adsorbed molecules and the metal surface are weakened and consequently, the adsorbed molecules could become easily removable. Such data explains the decrease in the inhibition efficiency with increasing temperature [22]. The positive adsorption equilibrium constant $\mathrm{K}_{\mathrm{F}}$ values are indication of favourable adsorption [23]. The parameter $\mathrm{n}_{\mathrm{F}}$ in the Freundlich isotherm relates to intensity of adsorption and it varies with heterogeneity of the material [24], 
Table 1. Thermodynamic parameters of the dioctyl phthalate inhibitor in $1.0 \mathrm{M} \mathrm{HCl}$ solution at different concentrations of the inhibitor.

\begin{tabular}{ccccccccccc}
\hline $\begin{array}{c}\text { Concentration } \\
\text { of inhibtor } \\
\left(\begin{array}{c}\text { moldm })^{-3} \text { in } 1.0 \\
\mathrm{M} \mathrm{HCl}\end{array}\right.\end{array}$ & $\begin{array}{c}\text { Activation energy } \\
\text { of Adsorption }\end{array}$ & $\begin{array}{c}\text { Heat of } \\
\text { Adsorption }\end{array}$ & $\begin{array}{c}\text { Enthalpy of adsorption and } \\
\text { Entropy of Adsorption }\end{array}$ & $\begin{array}{c}\text { Gibbs Free } \\
\text { Energy of } \\
\text { Adsorption }\end{array}$ \\
\hline Blank & 82.96 & 0.962 & & & 80.40 & -0.57 & 0.959 & & $\begin{array}{c}\Delta \mathrm{G}_{\text {ads }} \\
(\mathrm{kJ})\end{array}$ & $\boldsymbol{R}^{2}$ \\
$\mathbf{0 . 0 1}$ & 91.66 & 0.962 & -50.76 & 0.985 & 89.10 & -0.19 & 0.960 & -51 & 0.984 \\
$\mathbf{0 . 0 3}$ & 98.28 & 0.956 & -42.23 & 0.935 & 95.72 & 0.94 & 0.953 & -42.23 & 0.935 \\
$\mathbf{0 . 0 5}$ & 126.82 & 0.965 & -88.74 & 0.991 & 124.3 & 1.4 & 0.964 & -88.74 & 0.991 \\
$\mathbf{0 . 0 7}$ & 162.52 & 0.917 & -108.12 & 0.875 & 160.00 & 3.01 & 0.914 & -108.12 & 0.875 \\
\hline
\end{tabular}

Table 2. Values for adsorption studies of the inhibitor on mild steel in $1.0 \mathrm{M} \mathrm{HCl}$ solutions at different temperatures.

\begin{tabular}{cccccc}
\hline Temperature (K) & \multicolumn{2}{c}{ Langmuir Isotherm } & \multicolumn{3}{c}{ Freundlich Isotherm } \\
\hline & $\mathrm{K}_{\mathrm{L}}$ & $\boldsymbol{R}^{2}$ & $\mathrm{~K}_{\mathrm{F}}$ & $\mathrm{n}_{\mathrm{F}}$ & $\boldsymbol{R}^{2}$ \\
\hline 303 & 22 & 0.848 & 1.41 & 0.291 & 0.929 \\
$\mathbf{3 0 8}$ & 16.4 & 0.877 & 10.4 & 1.056 & 0.992 \\
313 & 13.2 & 0.619 & 3.75 & 0.805 & 0.98 \\
\hline
\end{tabular}

Key: $\mathrm{K}_{\mathrm{L}}=$ equilibrium constant for Langmuir isotherm, $\mathrm{K}_{\mathrm{F}}=$ equilibriumconstant for Freundlich isotherm, $\mathrm{n}_{\mathrm{F}}=$ adsorption intensity.

and the value is always positive, but not an integer, with typical value of 0.6 [25]. The average value of $\mathrm{n}_{\mathrm{F}}$ is 0.717 for the inhibitor in $1.0 \mathrm{M} \mathrm{HCl}$, a value not far from 0.6 , an indication that this adsorption process can reasonably be modelled by Freundlich isotherm and is heterogeneous [23].

3) Standard Free Energy of Adsorption $\Delta \mathbf{G}_{\text {ads }}^{0}$

The standard free energy of adsorption, $\Delta \mathrm{G}_{\text {ads }}^{\circ}$, which can characterize the interaction of adsorbed molecules and metal surface, was calculated using Equation 11. The values of $\mathrm{K}_{\mathrm{ads}}$ were determined from the different isotherm plots, and are represented in Table 3. The negative values of $\Delta \mathrm{G}_{\mathrm{ads}}^{\mathrm{o}}$ ensure the spontaneity of adsorption process and stability of the adsorbed layer on the aluminium surface. Generally, the values of $\Delta \mathrm{G}_{\text {ads }}^{0}$ below $-40 \mathrm{~kJ} / \mathrm{mol}$ are consistent with physisorption, while those above $-40 \mathrm{~kJ} / \mathrm{mol}$ involve chemisorptions mechanism [26]. From Table 3 all the values of the standard free energy of adsorption are negative. This indicates that the adsorption process is spontaneous. The values also, were found to be below $-40 \mathrm{~kJ} / \mathrm{mol}$; which concur with the physisorption mechanism earlier proposed for the adsorption process in $1.0 \mathrm{M}$ $\mathrm{HCl} /$ inhibitor solutions [27].

\section{4) Kinetic Studies}

The corrosion of mild steel follows a first order rate law with respect to the concentration of the inhibitor [28]. A decrease in the rate constant $k$, with 
Table 3. Values for the standard free energy of adsorption $\Delta \mathrm{G}^{\mathrm{o}}$ ads of the solution of the inhibitor in $1.0 \mathrm{M} \mathrm{HCl}$ at different temperatures.

\begin{tabular}{|c|c|c|c|c|}
\hline Isotherm & Temperature (K) & $\mathrm{K}_{\mathrm{ads}}$ & $R^{2}$ & $\mathrm{G}_{\mathrm{ads}}(\mathrm{kJ} / \mathrm{mol})$ \\
\hline \multirow{3}{*}{$\begin{array}{l}\text { 岑 } \\
\text { 离 } \\
\text { 苟 }\end{array}$} & 303 & 22 & 0.965 & -17.90 \\
\hline & 308 & 16.4 & 0.961 & -17.45 \\
\hline & 313 & 13.2 & 0.857 & -17.17 \\
\hline \multirow{3}{*}{ 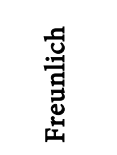 } & 303 & 1.41 & 0.782 & -10.98 \\
\hline & 308 & 10.4 & 0.907 & -16.28 \\
\hline & 313 & 3.75 & 0.996 & -13.89 \\
\hline
\end{tabular}

Table 4. Rate constant $k$, and half-life $t_{1 / 2}$ of mild steel in the inhibitor/1.0 M HCl solution at different temperatures.

\begin{tabular}{cccc}
\hline Temperature (K) & \multicolumn{3}{c}{ Rate Constant $\boldsymbol{k}\left(\mathrm{hr}^{-1}\right)$} \\
\hline 303 & 0.083 & $\boldsymbol{R}^{2}$ & $\boldsymbol{t}_{1 / 2}(\mathrm{hr})$ \\
\hline 308 & 0.056 & 0.892 & 8.351 \\
313 & 0.034 & 0.98 & 12.378 \\
& & 0.187 & 20.387 \\
\hline
\end{tabular}

increase in temperature indicates that the rate of the mild steel corrosion is greatly reduced in the presence of the inhibitor (dioctyl phthalate) in $1.0 \mathrm{M} \mathrm{HCl}$ medium. The half-life calculated from Equation (8), and presented in Table 4, indicated that the life span of the mild steel is increased as the temperature increased.

\section{Conclusion}

The inhibiting effect of dioctyl phthalate on the corrosion of mild steel was carried out in $1.0 \mathrm{M} \mathrm{HCl}$ solution and at a temperature range of 303 to $313 \mathrm{~K}$ using the weight loss method. The results obtained, showed that dioctyl phthalate is a good corrosion inhibitor of mild steel. The efficiency was found to decrease with increasing temperature and increase with increase in the concentration of the inhibitor in the media. The adsorption of the inhibitor on mild steel was found to be spontaneous. The most suitable isotherm to be used for modelling the corrosion inhibition studies of the dioctyl phthalate is the Freundlich adsorption isotherm. Physisorption mechanism was proposed for the adsorption of dioctyl phthalate in $1.0 \mathrm{M} \mathrm{HCl}$ solution on mild steel. It can therefore be recommended that more research should be carried out on the properties of dioctyl phthalate in corrosion inhibition using other methods, other than the weight loss method.

\section{Acknowledgements}

We wish to thank Gombe State University for providing the reagents for the research, and University of Jos for providing the Laboratory space and equipments required for the research work. 


\section{Conflicts of Interest}

The authors declare no conflicts of interest regarding the publication of this paper.

\section{References}

[1] Terrence, B. (2017) What Is Corrosion? The Balance. https://www.thebalance.com/what-is-corrosion-2339700

[2] Opila, E.J. and Jacobson, N.S. (1999) Corrosion of Ceramic Materials. NASA Lewis Research Center.

https://ntrs.nasa.gov/archive/nasa/casi.ntrs.nasa.gov/20000004900.pdf

[3] Barbra, S.A. and Robert, K.G. (2006) What Is Corrosion? The Electrochemical Society Interface, 1-3. https://www.electrochem.org/dl/interface/spr/spr06/spr06_p24-26.pdf

[4] Gräfen, H., Horn, E., Schlecker, H. and Schindler, H. (2002) Corrosion. In: Ullmann's Encyclopedia of Industrial Chemistry, Weinheim, Wiley-VCH.

[5] Finšgarand, M. and Milošev, I. (2010) Inhibition of Copper Corrosion by 1,2,3-benzotriazole: A Review. Corrosion Science, 52, 2737-2749. https://doi.org/10.1016/j.corsci.2010.05.002

[6] El-Sherif, R.M. and Badawy, W.A. (2011) Mechanism of Corrosion and Corrosion Inhibition of Tin in Aqueous Solutions Containing Tartaric Acid. International Journal of Electrochemical Science, 6, 6469-6482. http://electrochemsci.org/papers/vol6/6126469.pdf

[7] Onen, A.I., Nwufo, B.T., Ebenso, E.E. and Hlophe, R.M. (2010) Titanium (IV) Oxide as Corrosion Inhibitor for Aluminium and Mild Steel in Acidic Medium. International Journal of Electrochemical Science, 5, 1563-1573. http://electrochemsci.org/papers/vol5/5111563.pdf

[8] Antonijevic, M.M. and Petrovic, M.B. (2008) Copper Corrosion Inhibitors. A Review. International Journal of Electrochemical Science, 3, 1-28. https://www.researchgate.net/profile/Milan_Antonijevic2/publication/26495183_Co pper_Corrosion_Inhibitors_A_review/links/0046353023297b45dd000000/Copper-C orrosion-Inhibitors-A-review.pdf

[9] http://www.kat-chem.hu/en/prod-bulletins/dioktilftalat

[10] Amin, M.A., Abd El-Rehim, S.S., El-Sherbini, E.E.F. and Bayoumi, R.S. (2008) Chemical and Electrochemical (AC and DC) Studies on the Corrosion Inhibition of Low Carbon Steel in 1.0 M HCl Solution by Succinic Acid-Temperature Effect, Activation Energies and Thermodynamics of Adsorption. International Journal of Electrochemical Science, 3, 199-215. http://www.electrochemsci.org/papers/vol3/3020199.pdf

[11] Patel, N.S., Jauhariand, S., Mehta, G.N., Al-Deyab, S.S., Warad, I. and Hammouti, B. (2013) Mild Steel Corrosion Inhibition by Various Plant Extracts in 0.5 M Sulphuric Acid. International Journal of Electrochemical Science, 8, 2635-2655. http://electrochemsci.org/papers/vol8/80202635.pdf

[12] Ladd, M. (1998) Introduction to Physical Chemistry. 3rd Edition, Cambridge University Press, Cambridge, 426. https://doi.org/10.1017/CBO9781139170925

[13] Zarrouk, A., Hammouti, B., Zarrok, H., Al-Deyab, S.S. and Messali, M. (2011) Temperature Effect, Activation Energies and Thermodynamic Adsorption Studies of L-Cysteine Methyl Ester Hydrochloride as Copper Corrosion Inhibitor in Nitric 
Acid 2M. International Journal of Electrochemical Science, 6, 6261-6274.

http://repository.taibahu.edu.sa/bitstream/handle/123456789/6111/Temperature\%2 0Effect,\%20Activation\%20Energies\%20and\%20Thermodynamic\%20Adsorption\%2 0Studies\%20of\%20L-Cysteine\%20Methyl\%20Ester\%20Hydrochloride\%20As\%20Co pper\%20Corrosion\%20Inhibitor\%20In\%20Nitric\%20Acid\%202M.pdf?sequence=1

[14] Shukla, S.K. and Ebenso, E.E. (2011) Corrosion Inhibition, Adsorption Behavior and Thermodynamic Properties of Streptomycin on Mild Steel in Hydrochloric Acid Medium. International Journal of Electrochemical Science, 6, 3277-3291. http://electrochemsci.org/papers/vol6/6083277.pdf

[15] Zarrouk, A., Zarrok, H., Salghi, R., Bouroumane, Hammouti, B., Al-Deyab, S.S. and Touzani, R. (2012) The Adsorption and Corrosion Inhibition of 2-[Bis-(3,5-dimethyl-pyrazol-1-ylmethyl)-amino]-pentanedioic Acid on Carbon Steel Corrosion in $1.0 \mathrm{~m} \mathrm{HCl}$. International Journal of Electrochemical Science, 7, 10215-10232. http://electrochemsci.org/papers/vol7/71010215.pdf

[16] Neil, R.C. (1989) General Chemistry (PW. Atkins): Review. Journal of Chemical Education, 66, A187.

[17] Nair, R.N., Sharma, S., Sharma, I.K., Verma, P.S. and Sharma, A. (2010) Inhibitory Efficacy of Piper Nigrum Linn. Extract on Corrosion of AA1100 in HCL. Rasayan Journal of Chemistry, 3, 783-795. http://rasayanjournal.co.in/vol-3/issue-4/30.pdf

[18] Nnanna, L.A., Anozie, I.U., Avoaja, A.G.I., Akoma, C.S. and Eti, E.P. (2011) Comparative Study of Corrosion Inhibition of Aluminium Alloy of Type AA3003 in Acidic and Alkaline Media by Euphorbia hirta Extract. African Journal of Pure and Applied Chemistry, 5, 265-271.

http://www.academicjournals.org/journal/AJPAC/article-full-text-pdf/021613A1309

[19] Behpour, M., Ghoreishi, S.M., Soltani, N., Salavati-Niasari, M., Hamadanian, M. and Gandomi, A. (2008) Electrochemical and Theoretical Investigation on the Corrosion Inhibition of Mild Steel by Thiosalicylaldehyde Derivatives in Hydrochloric Acid Solution. Corrosion Science, 50, 2172-2181.

https://doi.org/10.1016/j.corsci.2008.06.020

[20] Onen A.I, Barminas, J.T, and Jacob, J. (2013) Inhibitory Action of Ficus carica Extracts on Aluminium Corrosion in Acidic Medium. Chemical Science Transaction, 2, 1326-1333.

[21] Pavithra, M.K., Venkatesha, T.V. and Punith Kumar, M.K. (2013) Inhibiting Effects of Rabeprazole Sulfide on the Corrosion of Mild Steel in Acidic Chloride Solution. International Journal of Electrochemistry, 1-9.

[22] Al-Dokheily, M.E., Kredy, H.M. and Al-Jabery, R.N. (2014) Inhibition of Copper Corrosion in $\mathrm{H}_{2} \mathrm{SO}_{4}, \mathrm{NaCl}$ and $\mathrm{NaOH}$ Solutions by Citrulluscolocynthis Fruits Extract. Journal of Natural Sciences Research, 4, 60-73.

https://www.researchgate.net/profile/Husam_Kredy/publication/277666019_Inhibit ion_of_Copper_Corrosion_in_H_2_SO_4_NaCl_and_NaOH_Solutions_by_Citrull us_colocynthis_Fruits_Extract/links/5933166645851553b6c30d58/Inhibition-of-Co pper-Corrosion-in-H-2-SO-4-NaCl-and-NaOH-Solutions-by-Citrullus-colocynthis -Fruits-Extract.pdf

[23] Adejo, S.O., Gbertyo, J.A. and Ahile, J.U. (2013) Inhibitive Properties and Adsorption Consideration of Ethanol Extract of Manihotesculentum Leaves for Corrosion Inhibition of Aluminium in $2 \mathrm{M} \mathrm{H}_{2} \mathrm{SO}_{4}$. International Journal of Modern Chemistry, 4, 137-146.

[24] Chatterjee, S., Lee, D.S., Lee, M.W. and Woo, S.H. (2009) Enhanced Adsorption of Congo Red from Aqueous Solutions by Chitosan Hydrogel Beads Impregnated with 
Cetyltrimethyl Ammonium Bromide. Bioresource Technology, 100, 2803-2809. https://doi.org/10.1016/j.biortech.2008.12.035

[25] Khadom, A.A., Yaro, A.S. and Abdul, A.H. (2010) Adsorption Mechanism of Benotriazole for Corrosion Inhibition of Coppper-Nickel Alloy in Hydrochloric Acid. Journal of Chilean Chemical Society, 55, 150-152. https://doi.org/10.4067/S0717-97072010000100035

[26] Popova, A., Sokolova, E., Raicheva, S. and Christov, M. (2003) AC and DC Study of the Temperature Effect on Mild Steel Corrosion in Acid Media in the Presence of Benzimidazole Derivatives. Corrosion Science, 45, 33-58.

[27] Adejo, S.O. and Ekwenchi, M.M. (2014) Proposing a New Empirical Adsorption Isotherm Known as Adejo-Ekwenchi Isotherm. IOSR Journal of Applied Chemistry, 6, 66-71.

https://www.researchgate.net/profile/Sylvester_Adejo/publication/269276792_PRO POSING_A_NEW_EMPIRICAL_ADSORPTION_ISOTHERM_KNOWN_AS_AD EJO-EKWENCHI_ISOTHERM/links/54bcf5be0cf24e50e940bac7.pdf

[28] Nwigbo, S.C., Okaforand, V.N. and Okewale, A.O. (2012) Comparative Study of ElaeisGuiniensis Exudates (Palm Wine) as a Corrosion Inhibitor for Mild Steel in Acidic and Basic Solutions. Research Journal of Applied Sciences, Engineering and Technology, 4, 1035-1039.

http://www.airitilibrary.com/Publication/alDetailedMesh?docid=20407467-201205201510220010-201510220010-1035-1039 